\title{
THE FIRST MINUTE OF LIFE: HOW DOES REAL LIFE COMPARE TO ALGORITHMS?
}

\author{
L. McCarthy ${ }^{1,2,3}$, C.P. O'Donnell ${ }^{1,2,3}$
}

${ }^{I}$ The National Maternity Hospital, ${ }^{2}$ The National Children's Research Centre, Crumlin, ${ }^{3}$ University College Dublin, Dublin, Ireland

Background: Within 30 seconds of birth ILCOR recommends that newborns should be warmed, have their airways opened and breathing and heart rate (HR) assessed. By 60 seconds, respiratory support given if appropriate and oximetry considered.

Objectives: To determine time taken to perform DR interventions recommended by ILCOR; and the proportion with the recommended interventions performed within the allotted time.

Methods: Using video recordings we measured the time taken to warm, assess HR, attach an oximeter and give respiratory support; and determined which infants had the recommended interventions completed by 30 and 60 seconds.

Results: We reviewed recordings of 23 infants [mean(SD) gestational age \& birth weight 29(3) weeks \& $1312(594) \mathrm{g}]$. All interventions took longer than recommended (Table1). Four infants were not on the trolley within 30 seconds. By 60 seconds, 10/21 infants were in polyethylene-bags, $3 / 23$ had their HR determined and 12/23 had an oximeter on. No infant had all tasks completed within 30 or 60 seconds of birth

\begin{tabular}{|l|c|c|}
\hline \multicolumn{1}{|c|}{ INTERVENTION N=23 } & FROM BIRTH Mean (SD) sec & $\begin{array}{c}\text { FROM ARRIVAL ON } \\
\text { TROLLEY Mean (SD) sec }\end{array}$ \\
\hline Placed on table & $19(10)$ & \\
\hline Polyethylene bag on (N=21) & $61(24)$ & $42(18)$ \\
\hline Airway opened & $123(134)$ & $104(135)$ \\
\hline HR first determined & $85(31)$ & $67(31)$ \\
\hline Pulse oximeter on & $69(28)$ & $50(28)$ \\
\hline $\begin{array}{l}\text { Any respiratory support given } \\
\text { (N=23) }\end{array}$ & $156(132)$ & $137(128)$ \\
\hline
\end{tabular}

[Time Taken to Complete DR Interventions]

Conclusion: Our newborns were not managed within the time-frame recommended by ILCOR. The 30second intervals recommended may be too short. 